\title{
MODELING TUTUPAN LAHAN di DAS TIKALA BERDASARKAN KAPASITAS SALURAN SUNGAI TIKALA
}

\section{MODELING LAND COVER FOR THE TIKALA WATERSHED BASED ON THE CHANEL CAPASITY OF TIKALA RIVER}

\author{
Heinsy Adriana Julia Telah1), Johan A. Rombang2), dan Hengki D. Walangitan2) \\ 1)Mahasiswa S1 Program Studi Ilmu Kehutanan, Fakultas Pertanian Unsrat Manado, 95115 \\ 2)Staf Pengajar PS. Ilmu Kehutanan, Jurusan Budidaya Pertanian, Fakultas Pertanian Unsrat Manado, 95115
}

\begin{abstract}
Tikala river is the main channel of Tikala watershed. Tikala watershed covers an area of $9215,89 \mathrm{~km}^{2}$ and the length of the main river is $23,73 \mathrm{~km}$. The decline in Tikala watershed quality is marked by high fluctuations of river debit, the increase of erosion and sedimentation rates, and destructive flood. Comparing to floods caused by other rivers in Manado city, flood caused by Tikala river on the 15th January 2014 was the worst case. For this reason, research was conducted to analyze the capacity of river channels in three sampling spots, chosen through purposive sampling methods, and to model types of landuse suitable to the capacity of river channels. Results of river channel capacity analysis at 3 sampling spots using Manning's equation were 45,29 m³/s, 131,58 m³/s, and 36,39 m3/s. Five models of landuse were carried out for Tikala Watershed and the most suitable landuse model is the 4th type in which open area, dry agriculture, and 4.099 ha of dry agriculture mixed with shrubs were converted into an agroforestry system.
\end{abstract}

Keywords: watershed, river capacity, modeling

\begin{abstract}
ABSTRAK
DAS Tikala memiliki sungai utama yaitu Sungai Tikala, DAS Tikala memiliki luas $9215,89 \mathrm{~km}^{2}$ dengan panjang sungai $23,73 \mathrm{~km}$. Akibat terjadi penurunan kualitas DAS Tikala ditandai dengan fluktuasi debit aliran sungai yang tinggi setiap tahun serta meningkatnya laju erosi dan sedimentasi, sehingga terjadi banjir yang merugikan banyak pihak. Banjir terjadi ketika curah hujan yang tinggi, intensitas curah hujan tinggi serta kerusakan yang terjadi akibat penggunaan lahan yang salah. Sungai Tikala merupakan sungai yang memberi dampak kerusakan terbesar pada banjir 15 Januari 2014. Pengambilan data dilakukan di 3 lokasi yang berada di daerah hilir yang dipilih dengan menggunakan metode purposive sampling serta merancang/modeling jenis dan luasan tutupan lahan yang sesuai dengan kapasitas saluran sungai. Hasil analisis kapasitas saluran sungai di 3 lokasi pengambilan data menggunakan persamaan Manning adalah 45,29 m³/s, 131,58 m³/s, 36,39 m³ serta pemodelan dilakukan sebanyak 5 kali dan modeling yang sesuai untuk DAS Tikala adalah modeling IV area tanah terbuka, pertanian lahan kering dan 4099 ha pertanian lahan kering campur semak belukar dialihfungsikan menjadi sistem agroforestri.
\end{abstract}

Kata kunci : daerah aliran sungai, kapasitas sungai, modeling 


\section{PENDAHULUAN}

Daerah Aliran Sungai (Watershed) atau disingkat DAS diartikan sebagai suatu wilayah daratan yang menerima air hujan, menampung, mengalirkannya melalui satu sungai utama ke laut atau danau. Satu DAS dipisahkan dari wilayah lain di sekitarnya oleh pemisah topografis seperti punggung bukit dan gunung yang masih terpengaruh oleh aktivitas daratan (Peraturan Pemerintah Nomor 37 tahun 2012). DAS terbagi lagi dalam DAS yang adalah bagian DAS yang menerima air hujan dan menggalirkannya melalui anak sungai ke sungai utama.

Penurunan mutu Daerah Aliran Sungai (DAS) di Indonesia telah menjadi keprihatinan nasional. Hal ini ditandai oleh fluktuasi debit aliran sungai yang tinggi setiap tahun serta meningkatnya laju erosi dan sedimentasi. Akibat yang ditimbulkannya adalah semakin seringnya kejadian banjir dan kekeringan, kurang efisiennya sistem irigasi karena tidak optimalnya distribusi air, penipisan lapisan olah pada lahan pertanian serta terjadinya pendangkalan waduk dari sungai akibat sedimentasi. Apabila masalah ini tidak ditangani segera, maka akan terjadi peningkatan laju penurunan produktivitas DAS dan pendapatan wilayah (Asdak, 2014).

Salah satu masalah yang sering dihadapi dalam DAS adalah banjir yang mengakibatkan kerusakan dan penurunan mutu DAS itu sendiri. Banjir dapat terjadi ketika curah hujan dengan intensitas yang tinggi dan kerusakan akibat penggunaan lahan yang salah.

Sulawesi Utara memiliki beberapa DAS dan salah satunya adalah DAS Tikala yang merupakan bagian dari sub DAS Tondano yang memiliki luas $9215,49 \mathrm{~km}^{2}$ dan panjang $23,73 \mathrm{~km}$, dan memiliki sungai utama yaitu sungai Tikala. Hulu Sungai Tikala berasal dari lereng utara Gunung Mahawu dan mengalir melalui Desa Rumengkor, Sampiri, Kaleosan, Sawangan (Kecamatan Tombulu), Tikela, Paal IV, Tikala Baru, Banjer, Tikala Ares, dan berakhir di kelurahan Tikala. Data BPDAS Tondano, Sungai Tikala adalah sungai yang memberi dampak kerusakan terbesar saat banjir 15 Januari 2014 dengan ketinggian air berkisar 8-9 m, menggenangi
9 kelurahan, serta menghanyutkan 18 rumah (BPDAS, 2014).

Kapasitas saluran sungai dalam mengalirkan air ditentukan oleh karakteristik sungai yang terdiri dari kemiringan lantai/dasar sungai, kekasaran permukaan yang dilewati oleh air, jari-jari hidrolik dan luas penampang melintang sungai. Apabila kapasitas aliran sungai terlampaui maka akan terjadi luapan (banjir) di sekitar saluran sungai. Perubahan morfologi dan permukaan suatu sungai berpengaruh terhadap fungsi sungai dalam mengalirkan air limpasan atau larian dan koefisien kekasaran suatu sungai. Jenis dan luasan tutupan lahan di DAS Tikala saat ini meliputi hutan lahan kering sekunder, semak belukar, pemukiman, tanah terbuka, pertanian lahan kering dan pertanian lahan kering campur semak (BPDAS, 2016).

Penelitian ini bertujuan untuk menghitung kapasitas saluran Sungai Tikala di daerah hilir dan memodeling jenis dan luasan tutupan lahan DAS Tikala yang sesuai kapasitas saluran sungai. Penelitian ini diharapkan dapat memberikan data dan informasi mengenai berapa besar nilai kapasitas saluran Sungai di daerah hilir Sungai Tikala serta jenis dan luasan tutupan lahan yang ekologis bagi DAS Tikala.

\section{METODE PENELITIAN}

Penelitian ini dilaksanakan di DAS Tikala dan di Laboratorium SIG Program Studi IImu Kehutanan Unsrat pada bulan Oktober-Januari 2017.

Alat dan bahan yang digunakan dalam penelitian ini adalah GPS, Current meter, Clinometer, Meteran, tongkat, Alat Tulis Menulis, Kalkulator, Kamera, Laptop, Perangkat lunak SIG, Peta Rupa Bumi (RBI) Provinsi Sulawesi Utara, Skala 1: 50.000 (Bakosurtanal), Peta Kawasan Hutan dan Konservasi Perairan Provinsi Sulawesi Utara, Skala 1 : 250.000 (Lamp.Keputusan Menteri Kehutanan Nomor: 734/KPTS-II/2014, Tanggal 2 September 2014), Peta batas DAS Tikala (BPDAS Tondano) dan peta tutupan lahan DAS Tikala (BPDAS Tondano dan BPKH Manado), Peta RTRW Kab.Minahasa, Kota Tomohon dan Kota Manado. 
Penelitian ini dilakukan menggunakan metode survei dan penentuan lokasi pengukuran dan pengamatan berdasarkan pertimbangan tertentu (purposive sampling). Titik lokasi pengamatan kapasitas saluran sungai diambil didaerah hilir dimana saluran sungai menyempit akibat padatnya pemukiman. Analisis data spasial menggunakan perangkat lunak SIG dan perhitungan kapasitas saluran sungai, koefisien limpasan DAS serta modeling luasan dan jenis tutupan lahan yang sesuai menggunakan perangkat lunak excel.

Variabel yang diamati yaitu lebar sungai, lebar basah sungai, lebar dasar sungai, kedalaman air sungai, kedalaman sungai, bentuk profil melintang sungai, kecepatan aliran sungai, kemiringan lantai/dasar sungai, dan kondisi saluran sungai.

Analisis kapasitas saluran sungai dianalisis dengan persamaan Manning, persamaan Manning digunakan untuk menyatakan tingkat kekasaran permukaan (Indarto, 2010). Analisis koefisien limpasan DAS dihitung dan debit puncak limpasan dihitung untuk intensitas curah hujan $50 \mathrm{~mm} / \mathrm{jam}$ dan 100 $\mathrm{mm} / \mathrm{jam}$ dianalisis dengan persamaan rasional serta hasil koefisien limpasan DAS untuk modeling tutupan lahan agar nilai koefisien limpasannya bila digunakan dalam persamaan rasional menghasilkan debit yang sama atau lebih kecil dari kapasitas saluran sungai. Model-model tutupan lahan tersebut kemudian dibandingkan tutupan lahan existing dan tutupan lahan sesuai RTRW.

$\begin{gathered}\text { Persamaan Man } \\ R^{2 / 3} \cdot S^{1 / 2}\end{gathered}$
$v=\frac{n}{-\cdot--}$

Metode Rasional :

$Q=0,0028$ C i A

\section{HASIL DAN PEMBAHASAN}

\section{Deskripsi Area Penelitian \\ Lokasi Pengambilan Data}

Lokasi pengambilan data primer dilakukan di sungai utama DAS Tikala yaitu Sungai Tikala, Lokasi pengamatan pertama Kelurahan Tikala dengan koordinat (124 $51^{\prime} 8.049^{\prime \prime} \mathrm{T}, 1^{\circ} 28^{\prime} 58.616^{\prime \prime}$ $\mathrm{U})$, lokasi pengamatan kedua di Kelurahan Perkamil dengan koordinat $\left(124^{\circ} 52^{\prime} 20.176 " \mathrm{~T}, 1^{\circ} 28^{\prime} 15.130^{\prime \prime}\right.$ U ), dan Lokasi pengambilan data ketiga yaitu kelurahan Malendeng dengan koordinat ( $124^{\circ} 52^{\prime}$ $\left.55.213^{\prime \prime} \mathrm{T}, 1^{\circ} 27^{\prime} 43.915 " \mathrm{U}\right)$.

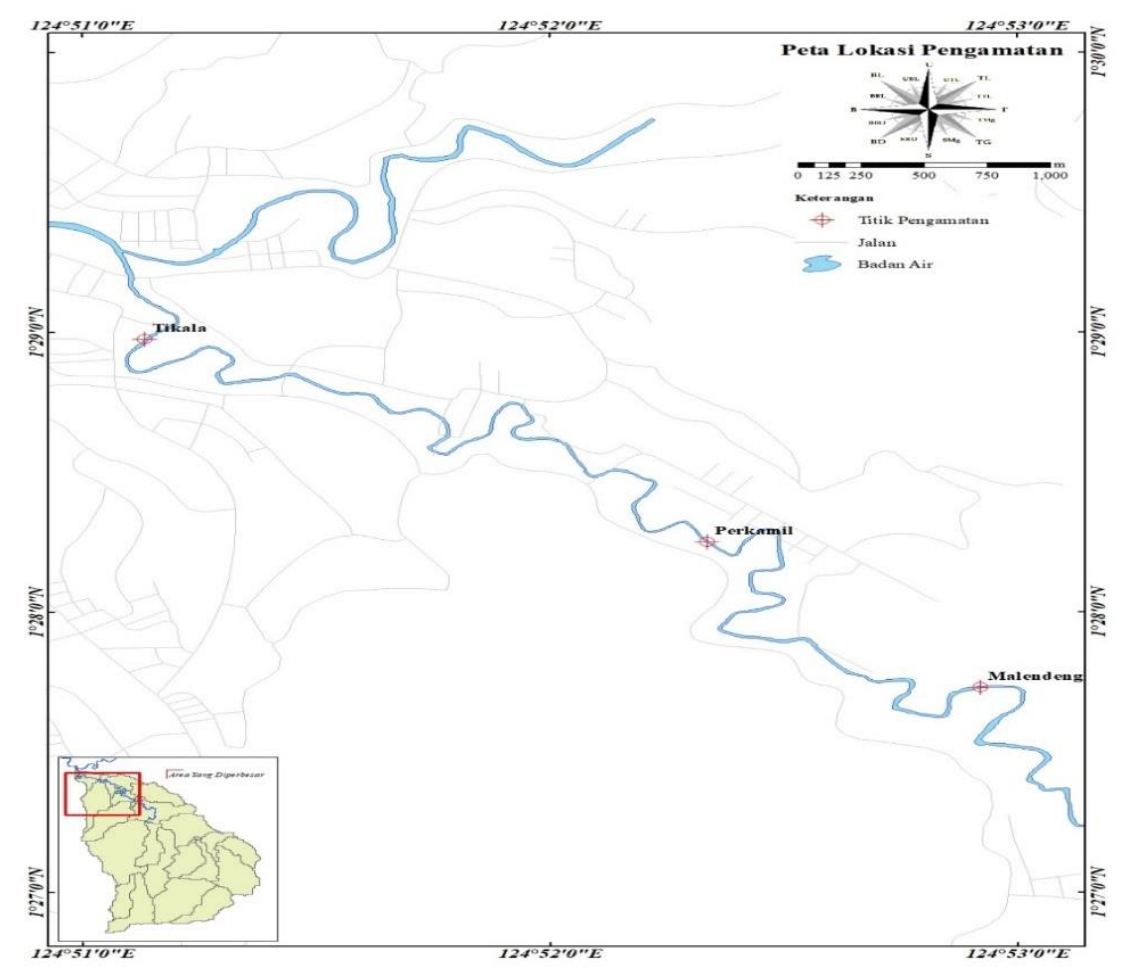

Gambar 1. Peta Lokasi Pengamatan (Sumber, Google Earth 2017)

(Figure 1. Observation Location Map (Source, Google Earth 2017)) 


\section{Jenis dan Luasan Tutupan Lahan DAS Tikala}

Tabel 1. Jenis dan Luasan Tutupan Lahan

(Table 1. Land Cover Type and Area)

\begin{tabular}{clcc}
\hline No. & \multicolumn{1}{c}{ Keterangan } & $\begin{array}{c}\text { Luas } \\
(\text { ha })\end{array}$ & $\begin{array}{c}\text { Luas } \\
(\%)\end{array}$ \\
\hline 1. & Hutan lahan kering sekunder & 150,72 & 7,5 \\
2. & Semak belukar & 663,23 & 8,3 \\
3. & Pemukiman & 806,64 & 9,9 \\
4. & Tanah terbuka & 2,63 & 0,2 \\
5. & Pertanian lahan kering & 992,84 & 31,1 \\
6. & Pertanian lahan kering campur semak & 6599,44 & 42,9 \\
\hline & $\quad$ Total Luas DAS Tikala & 9215,49 & 100 \\
\hline
\end{tabular}

Sumber: BPDAS 2016

Tabel 2. Waktu Konsentrasi

(Table 2. Time of Concentration)

\begin{tabular}{cc}
\hline Lokasi & $\begin{array}{c}\text { Waktu Konsentrasi } \\
(\text { Jam })\end{array}$ \\
\hline Malendeng & 5,16 \\
Perkamil & 5,54 \\
Tikala & 7,51 \\
\hline
\end{tabular}

Jenis dan luasan tutupan lahan dapat mempengaruhi mutu suatu DAS, dengan berkembangnya zaman tak dapat dipungkiri bahwa perubahan jenis dan luasan tutupan lahan di DAS Tikala ikut berubah dari tahun ketahun. Tabel 1 menjelaskan tentang presentase dari jenis dan luas tutupan lahan yang ada saat ini. Pada Tabel 1 menunjukan bahwa luas area hutan hanya $7.5 \%$ dari keseluruhan luas wilayah DAS Tikala. Menurut undang-undang No. 41 tahun 1999 tentang kehutanan menuliskan bahwa areal hutan yang ideal untuk suatu DAS adalah $30 \%$ dari keseluruhan luas wilayah DAS.

\section{Waktu Konsentrasi $\left(T_{c}\right)$ Untuk DAS Tikala}

Waktu konsentrasi $\left(T_{c}\right)$ merupakan waktu yang dibutuhkan oleh air untuk mengalir dari hulu ke hilir (Asdak, 2014). Waktu konsentrasi yang dihitung dengan menggunakan persamaan Kirpich dalam Asdak (2014). Tabel 2 merupakan hasil analisis dari waktu konsetrasi di tiga lokasi pengambilan data.
Berdasarkan Tabel 2 menunjukkan bahwa dibutuhkan waktu 7,51 jam oleh air hujan dari Hulu untuk sampai di lokasi pengamatan Tikala, sedangkan untuk lokasi pengamatan Perkamil dibuntuhkan 5,54 jam oleh air dari titik tejauh (hulu) ke lokasi pengamatan dan yang terakhir adalah lokasi pengamatan Malendeng dimana waktu yang dibutuhkan air hujan mengalir dari titik terjauh ke lokasi pengamatan adalah 5,16 jam.

\section{Deskripsi Saluran Sungai \\ Lokasi Malendeng}

Pengambilan data dilokasi Malendeng, diketahui bahwa lebar penampang sungai $18,9 \mathrm{~m}$, dasar sungai berpasir, disamping kiri kanan sungai ditumbuhi rumput dengan kondisi air mulai keruh. Disekitar lokasi pengamatan ini belum ada bangunan permanen. Hasil pengukuran dilokasi ini menunjukkan bahwa lokasi ini memiliki bentuk penampang Trapesium yang tidak sempurna, batas air untuk penampang basah adalah 1,9 m. 


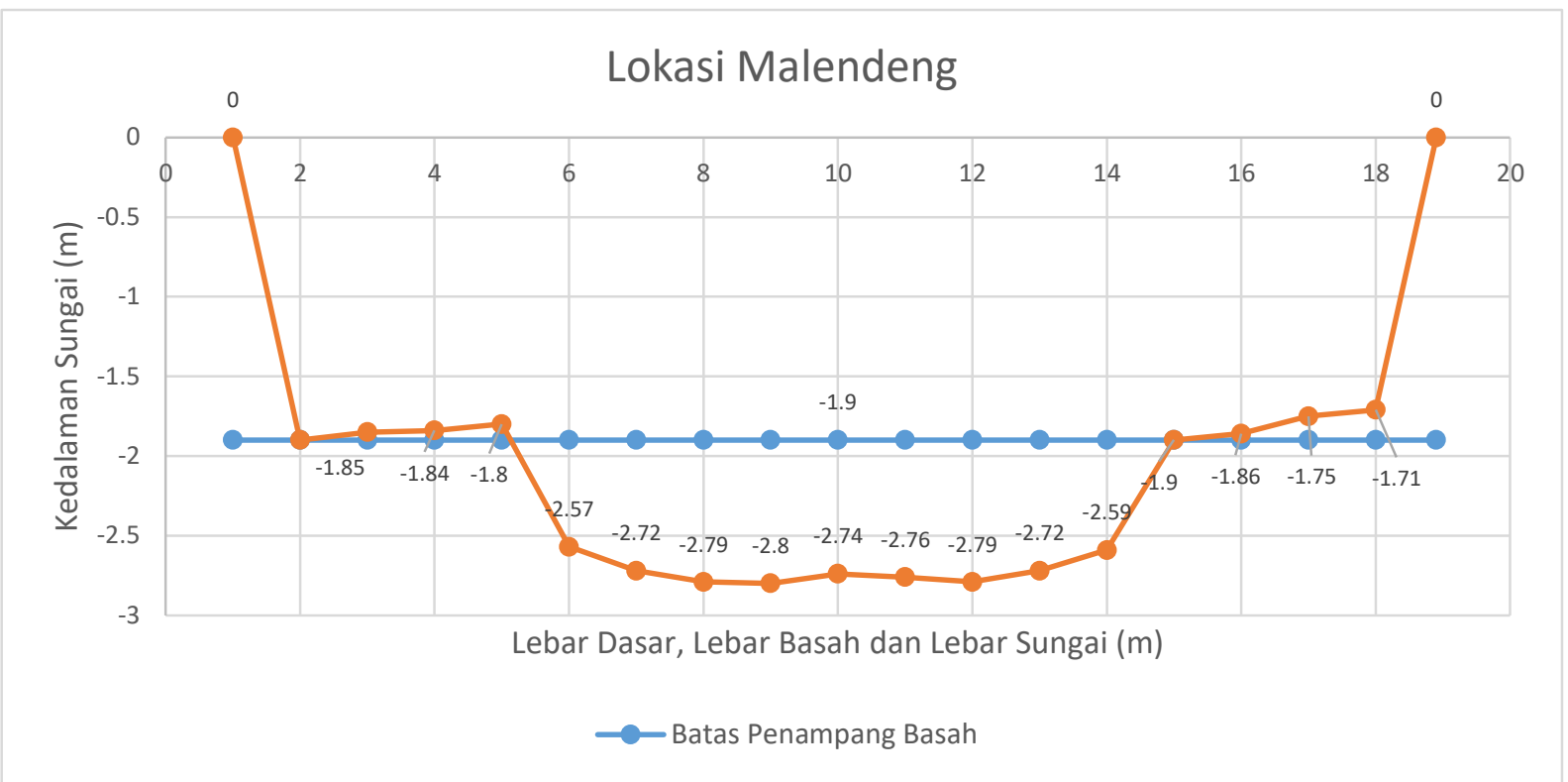

Gambar 2. Bentuk Penampang Malendeng

(Figure 2. Cross Section of Malendeng)

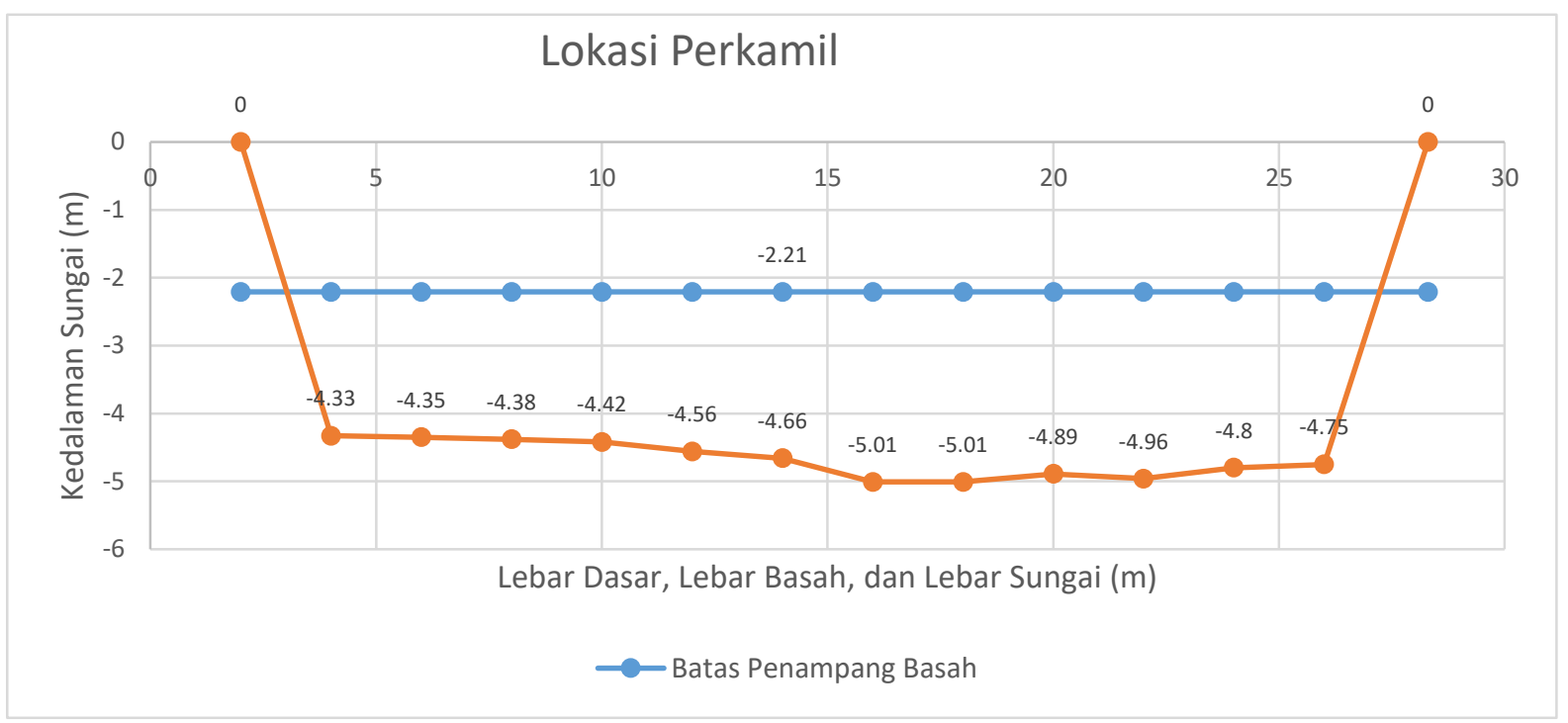

Gambar 3. Bentuk Penampang Perkamil

(Figure 3. Cross Section of Perkamil)

\section{Lokasi Perkamil}

Lokasi pengamatan Perkamil memiliki lebar sungai 28,3 $\mathrm{m}$ dan dasar sungai di lokasi ini berpasir campur lumpur sehingga banyak tumbuhan air yang tumbuh dibadan air, disisi kanan sungai telah dibangun dinding beton dan dibagian kiri sungai tanah yang ditumbuhi vegetasi. Lokasi pengamatan ini berada dipemukiman penduduk dengan kondisi air keruh, sedangkan bentuk penampang lokasi ini adalah Trapesium.

\section{Lokasi Tikala}

Lokasi pengambilan data Tikala, berada di daerah padat penduduk dengan lebar sungai 18,3 m. Kondisi dasar sungai berlumpur dan terdapat banyak sampah di saluran air serta air sangat keruh, bagian kiri dan kanan sungai adalah beton dan sebagian tanah. 


\section{Lokasi Tikala}

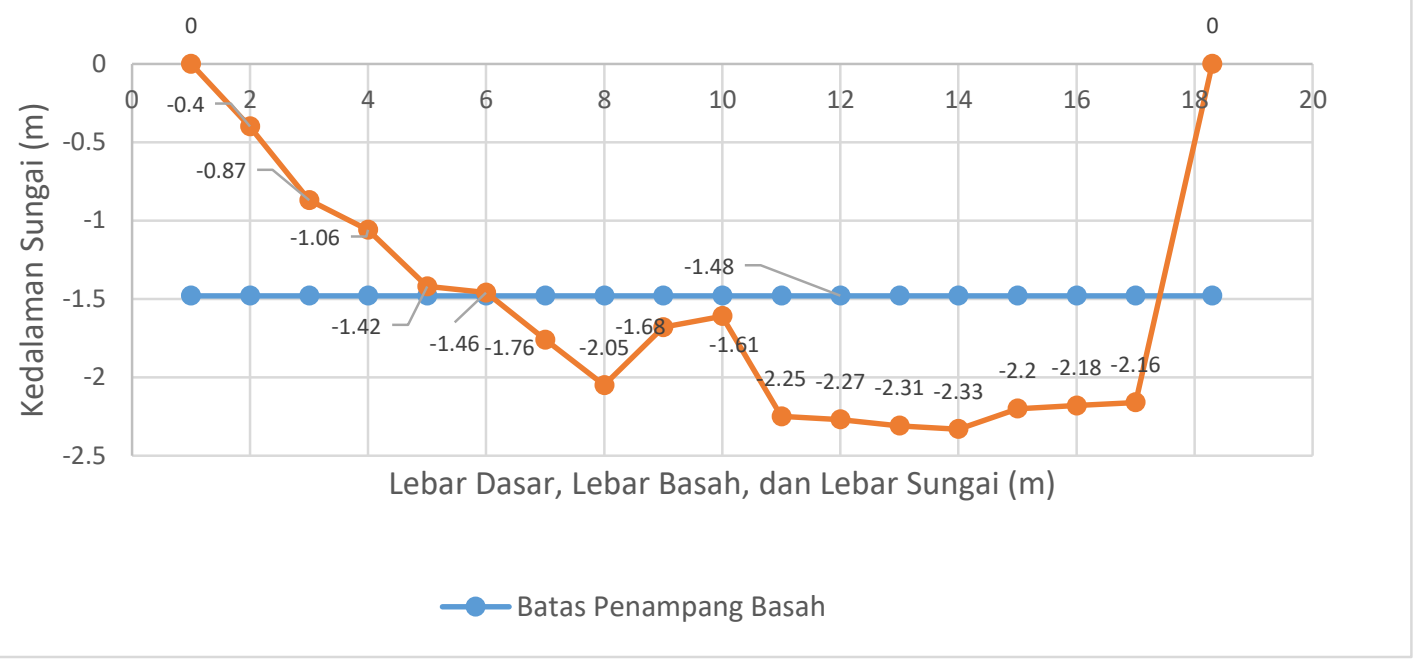

Gambar 4. Bentuk Penampang Tikala

(Figure 4. Cross Section of Tikala)

\section{Koefisien Kekasaran Sungai}

Berdasarkan persamaan Manning didapatkan nilai koefisien kekasaran sungai di tiga lokasi pengambilan data dalam Tabel 3.

Tabel 3 menunjukkan bahwa koefisien kekasaran sungai di Lokasi Malendeng memiliki nilai kekasaran sungai yang lebih besar dari kedua lokasi pengamatan lainnya, jika dibandingkan dengan data sekunder, maka lebih mendekati daerah banjir dengan padang rumput tanpa tumbuhan bawah, untuk nilai koefisien kekasaran Manning dengan nilai minimum 0,025 , rata-rata 0,030 , dan maksimum 0,035 , dapat dilihat bahwa nilai koefisien kekasaran sungai di ketiga lokasi pengamatan lebih rendah dari data sekunder. Perbedaan nilai kekasaran sungai di tiga lokasi disebabkan karena deskripsi sungai, kemiringan lantai sungai, dan jari-jari hidrolik yang berbeda. Nilai kekasaran sungai di lokasi pengambilan data Perkamil lebih rendah dibandingkan lokasi pengamatan Tikala dan lokasi pengambilan data Malendeng, sehingga nilai koefisien kekasaran sungai yang rendah akan mengakibatkan debit puncak yang besar dan aliran yang cepat.

\section{Kecepatan Aliran Maksimum Sungai Tikala}

Kecepatan aliran sungai diperoleh dari persamaan Manning,. Persamaan Manning meng- elaborasi kedalaman, kemiringan, jari-jari hidrolik dan kekasaran saluran terhadap kecepatan dan debit dalam saluran sungai (Indarto, 2016). Berdasarkan hasil pengukuran di lapangan bahwa Tabel 4. menunjukkan Jari-jari Hidrolik $R$, kemiringan saluran sungai $S$, dan kecepatan aliran maksimum $V$, di tiga lokasi pengambilan data.

Berdasarkan Tabel 4, Jari-jari Hidrolik $R$ yang terpanjang adalah lokasi perkamil sebesar 2,17 $\mathrm{m}$, diikuti Malendeng dan terpendek lokasi Tikala. Perbedaan panjang jari-jari Hidrolik $R$ disebabkan karena perbedaan lebar sungai di masing-masing lokasi. Selanjutnya kemiringan saluran menunjukkan bahwa lokasi Tikala adalah lokasi dengan kemiringan yang lebih tinggi di antara dua lokasi lainnya, walaupun dengan perbedaan yang tidak begitu jauh dengan lokasi perkamil dengan selisih 0,0001 dan kemiringan yang paling rendah adalah lokasi malendeng dengan kemiringan 0,0002. Kecepatan aliran sungai di lokasi Perkamil mencapai $2,00 \mathrm{~m} / \mathrm{s}$, disebabkan karena kemiringan yang tinggi dan lebar jari-jari hidrolik, selanjutnya lokasi Tikala dengan kecepatan saluran $1,61 \mathrm{~m} / \mathrm{s}$, walaupun kemiringan saluran lokasi ini yang tertinggi akan tetapi jari-jari hidroliknya yang paling pendek maka mengakibatkan kecepatan aliran sungai di lokasi ini lebih rendah dibandingkan lokasi Perkamil. Dan 
lokasi pengambilan data yang memiliki kecepatan aliran yang kecil adalah lokasi Malendeng yaitu 0,97 $\mathrm{m} / \mathrm{s}$ dikarenakan kemiringan yang rendah. Perbedaan kecepatan aliran sungai yang berbedabeda dipengaruhi oleh muatan dari aliran sungai yang berbeda, selain karena faktor kemiringan saluran $S$ dan jari-jari hidrologi $R$.

\section{Kapasitas Saluran Sungai}

Kapasitas saluran sungai merupakan berapa besar daya tampung suatu sungai dalam mengalirkan debit aliran air permukaan. Tabel 5 menunjukkan tentang kapasitas saluran sungai di tiga lokasi pengambilan data di sungai Tikala.

Berdasarkan Tabel 5 menunjukkan bahwa kapasitas saluran sungai untuk lokasi Perkamil memiliki daya tampung yang besar di bandingkan lokasi Tikala dan Malendeng itu disebabkan oleh luas penampang $A$ dan kecepatan aliran maksimum $\checkmark$ yang lebih besar.
Rinaldi, et.al. (2018) mengemukakan bahwa kapasitas tampung saluran sungai yang semakin mengecil, akan menyebabkan elevasi permukaan air meningkat, oleh sebab itu akan memberikan peluang yang lebih besar untuk air melimpas.

\section{Debit Maksimum DAS Tikala}

Tabel 6 adalah hasil analisis debit maksimum DAS Tikala dengan menggunakan dua asumsi intensitas curah hujan. Dua asumsi curah hujan ini digunakan berdasarkan kriteria curah hujan rendah dan menengah serta mempertimbangkan intensitas curah hujan yang terjadi pada tahum 2014 (saat banjir bandang) yaitu sebesar 120-180 $\mathrm{mm} / \mathrm{jam}$. Prediksi debit maksimum ini menggunakan koefisien aliran permukaan untuk tutupan lahan saat ini.

Tabel 3. Koefisien Kekasaran Sungai

(Table 3. River Roughness Values)

\begin{tabular}{cc}
\hline Lokasi & Nilai Koefisien Kekasaran Sungai \\
\hline Malendeng & 0,022 \\
Perkamil & 0,019 \\
Tikala & 0,020 \\
\hline
\end{tabular}

Tabel 4. Jari-jari Hidrolik, Kemiringan Dasar Saluran Sungai dan Kecepatan Aliran Sungai

(Table 4. Hydraulic Radius, Slope and Speed of River Channel)

\begin{tabular}{cccc}
\hline Lokasi & $\mathrm{R}(\mathrm{m})$ & $\mathrm{S}(\mathrm{m} / \mathrm{m})$ & $\mathrm{V}(\mathrm{m} / \mathrm{s})$ \\
\hline Malendeng & 1,90 & 0,0002 & 0,97 \\
Perkamil & 2,17 & 0,0005 & 2,00 \\
Tikala & 1,55 & 0,0006 & 1,61 \\
\hline
\end{tabular}

Tabel 5. Kapasitas Saluran Sungai

(Table 5. River Capacity)

\begin{tabular}{cc}
\hline Lokasi & Kapasitas Saluran Sungai $\left(\mathrm{m}^{3} / \mathrm{s}\right)$ \\
\hline Malendeng & 36,39 \\
Perkamil & 131,58 \\
Tikala & 45,29 \\
\hline
\end{tabular}

Tabel 6. Debit Maksimum DAS Tikala

(Table 6. Maximum Discharge of Tikala Watershed)

\begin{tabular}{cc}
\hline Curah Hujan $(\mathrm{mm} / \mathrm{jam})$ & Debit Maksimum $\left(\mathrm{m}^{3} / \mathrm{s}\right)$ \\
\hline 50 & 181,25 \\
100 & 362,51 \\
\hline
\end{tabular}


Berdasarkan Tabel 6 menunjukkan bahwa perkiraan debit puncak di DAS Tikala dengan intensitas curah hujan $50 \mathrm{~mm}^{3} / \mathrm{jam}$ adalah 181,25 $\mathrm{m}^{3} / \mathrm{s}$ dan untuk intensitas curah hujan $100 \mathrm{~mm}^{3} / \mathrm{jam}$ adalah $362,51 \mathrm{~mm}^{3} / \mathrm{s}$.

\section{Modeling Tutupan Lahan DAS Tikala}

Modeling tutupan lahan adalah perbandingan replikasi sistem dengan perbandingan tertentu, sesuatu yang mengandung empiris, suatu konsep atau suatu seri sistem statistik atau matematis yang menggambarkan sistem (Indarto, 2016). Tabel 7 menunjukkan tentang hasil analisis koefisien aliran permukaan dan debit puncak dengan asumsi intensitas curah hujan 50 mm/jam dan 100 $\mathrm{mm} / \mathrm{jam}$.

Tabel 7 menjelaskan tentang hasil analisis koefisien aliran permukaan saat ini dan koefisien aliran permukaan untuk keempat modeling tutupan lahan, serta debit puncak masing-masing modeling. Untuk model dengan tutupan lahan sistem agroforestri, koefisien aliran permukaan yang digunakan adalah koefisien aliran permukaan hutan sekunder karena sampai saat penelitian ini dilaksanakan, belum ditemukan nilai koefisien aliran permukaan untuk sistem afrogorestri. Untuk koefisien aliran permukaan saat ini di DAS Tikala adalah 0,140 sehingga dapat di lihat dalam Tabel 9 tentang debit maksimum DAS Tikala, sehingga DAS Tikala hanya mampu menampung aliran air maksimum sebesar $181,19 \mathrm{~m}^{3} / \mathrm{s}$ untuk intensitas curah hujan $50 \mathrm{~mm} / \mathrm{jam}$ dan $362,38 \mathrm{~m}^{3} / \mathrm{s}$ untuk curah hujan $100 \mathrm{~mm} / \mathrm{jam}$. Jika di bandingkan dengan kapasitas saluran sungai saat ini dapat dilihat di Tabel.7 maka akan melampaui kapasitas sungai saat ini, oleh karena itu di buatlah ke-IV modeling tutupan lahan di DAS Tikala untuk melihat berapa besar tutupan lahan yang ideal agar tidak terjadi banjir atau luapan air dari sungai.

Luas tutupan lahan saat ini dan luas modeling tutupan lahan disajikan dalam Tabel 8 demikian juga perubahan luas tutupan lahan.Dalam Tabel 8, hutan lahan kering sekunder dan agroforetri disamakan karena sistem agroforestri memiliki komposisi tanaman yang beragam antara tanaman kehutanan dan pertanian sehingga sistem agroforestri memiliki fungsi ekologis menyerupai hutan dan sistem agroforetri juga memiliki fungsi ekonomi yang lebih baik dibandingkan sistem pertanian.

\section{Modeling I (Area tanah terbuka di alih fungsi ke hutan)}

Modeling yang pertama mencoba alih fungsi area tanah terbuka menjadi hutan lahan kering sekunder, tanah terbuka dikonversikan ke hutan karena tanah terbuka memiliki nilai koefisien yang tinggi diantara tutupan lahan lainnya di DAS Tikala, nilai koefisien tanah terbuka adalah 0,2 dengan luas 2,63 ha. Sehingga luasan hutan lahan kering sekunder yang semula sebesar 150,73 ha menjadi 153,35 ha dengan koefisien limpasan 0,03. Dengan menggunakan modeling yang pertama ini, debit limpasan puncak adalah $155,603 \mathrm{~m}^{3} / \mathrm{s}$ untuk curah hujan $50 \mathrm{~mm} / \mathrm{jam}$ dan $311,20 \mathrm{~m}^{3} / \mathrm{s}$ untuk curah hujan $100 \mathrm{~mm} / \mathrm{jam}$ jumlah ini jauh lebih besar dibandingkan kapasitas saluran sungai.

\section{Modeling II (Area Pertanian di alih fungsi ke sistem Agroforestri)}

Modeling yang kedua adalah area pertainan lahan kering di alih fungsi ke sistem agroforestri, dimana dengan sistem ini jika diaplikasikan menjadi sistem agroforestri yang kompleks akan mejadi sistem pertanian yang menetap dan menyerupai hutan. Setelah mencoba rancangan/modeling yang pertama didapatkan hasil yang belum bias menampung debit limpasan puncak dengan intensitas curah hujan $50 \mathrm{~mm} / \mathrm{jam}$ dan $100 \mathrm{~mm} / \mathrm{jam}$ yang sesuai dengan kapasitas sungai yang ada saat ini, maka dicobalah modeling tutupan lahan yang kedua ini, area pertanian dengan nilai koefisien limpasan 0,1 akan dirubah ke sistem agroforestri sehingga nilai koefisien limpasan menjadi lebih kecil yaitu sebesar 0,03 sehingga didapatkan hasil debit limpasan puncak sebesar $181,19 \mathrm{~m} / \mathrm{s}$ dan 362,38 $\mathrm{m}^{3} / \mathrm{s}$ dengan curah hujan $50 \mathrm{~mm} / \mathrm{jam}$ dan 100 $\mathrm{mm} / \mathrm{jam}$. Nilai yang didapatkan ini masih jauh lebih besar dari nilai kapasitas saluran sungai di DAS Tikala saat ini.

\section{Modeling III (Area Hutan 30\% dari wilayah DAS)}

Area hutan sebesar $30 \%$ dari wilayah DAS Tikala merupakan modeling yang ketiga. Penetapan $30 \%$ area hutan merujuk kepada undang-undang 
Republik Indonesia nomor 41 tahun 1999. 30\% dari total luas DAS Tikala adalah 2764,45 ha sehingga luas hutan dari modeling 2 yaitu 1146,16 ha sekarang menjadi 2764,45 ha dan didapatkan hasil dari aliran air maksimum $171,46 \mathrm{~m}^{3} / \mathrm{s}$ dengan curah hujan $50 \%$ dan $342,92 \mathrm{~m}^{3} / \mathrm{s}$ untuk curah hujan 100 $\mathrm{m}^{3} / \mathrm{s}$. Untuk modeling yang ketiga ini masih melampaui kapasitas saluran sungai DAS Tikala (Tabel 5).

\section{Modeling IV (Area Tanah Terbuka, Pertanian Lahan Kering dan 4099 Ha Pertanian Lahan Kering Campur Semak Belukar di Alihfungsikan menjadi sistem Agroforestri)}

Hasil dari ketiga modeling tutupan lahan yang ada ternyata melebihi kapasitas saluran sungai
DAS Tikala (Tabel 5). Maka dibuatlah modeling yang ke empat ini, untuk 4099 ha pertanian lahan kering campur semak belukar ditentukan berdasarkan kemiringan lereng dan daerah yang dekat dengan pemukiman. Hasil dari rancangan/modeling ini mendapatkan hasil aliran maksimum sebesar $131,29 \mathrm{~m} / \mathrm{s}$ untuk curah hujan $50 \mathrm{~mm} / \mathrm{jam}$ dan untuk curah hujan $100 \mathrm{~mm} / \mathrm{jam}$ mendapatkan hasil aliran air maksimum sebesar 262,58 $\mathrm{m}^{3} / \mathrm{s}$. Untuk aliran air maksimum dengan intensitas curah hujan 50 $\mathrm{mm} / \mathrm{jam}$ dapat ditampung untuk kapasitas sungai yang ada (Tabel 5) sedangkan untuk curah hujan $100 \mathrm{~mm} / \mathrm{jam}$ masih akan terjadi luapan/banjir.

Tabel 7. Hasil Analisis Koefisien Aliran Permukaan dan Debit Maksimum

(Table 7. Results of Coefficient Run Off and Peak Discharge Analysis)

\begin{tabular}{|c|c|c|c|c|}
\hline \multirow{2}{*}{$\begin{array}{c}\text { Koefisien } \\
\text { Aliran Permukaan } \\
\text { Saat Ini }\end{array}$} & \multirow{2}{*}{\multicolumn{2}{|c|}{$\begin{array}{c}\text { Koefisien Aliran Permukaan } \\
\text { Modeling }\end{array}$}} & \multicolumn{2}{|c|}{ Debit Maksimum $\left(\mathrm{m}^{3} / \mathrm{s}\right)$} \\
\hline & & & 50 mm/jam & 100 mm/jam \\
\hline \multirow[t]{5}{*}{0,140} & I & 0,121 & 181,19 & 362,38 \\
\hline & II & 0,140 & 155,60 & 311,20 \\
\hline & III & 0,133 & 171,46 & 342,92 \\
\hline & IV & 0,102 & 131,29 & 262,58 \\
\hline & V & 0,130 & 167,99 & 335,98 \\
\hline
\end{tabular}

Tabel 8. Luas Tutupan Lahan dan Luas Modeling Tutupan Lahan

(Table 8. Land Cover Area and Modeling Land Cover Area)

\begin{tabular}{cccccc}
\hline \multirow{2}{*}{ Keterangan } & \multicolumn{5}{c}{ Luas } \\
\cline { 2 - 6 } & Existing & Modeling I & Modeling II & Modeling III & Modeling IV \\
\hline Hutan Lahan kering sekunder/ & 150,72 & 2764,64 & 153,34 & 1146,18 & 5245,19 \\
Agroforestri & 663,22 & 663,22 & 663,22 & 663,22 & 663,22 \\
Semak belukar & 806,64 & 806,64 & 806,64 & 806,64 & 806,64 \\
Pemukiman & 2,62 & 0,00 & 0,00 & 0,00 & 0,00 \\
Tanah terbuka & 992,83 & 554,35 & 992,83 & 0,00 & 0,00 \\
Pertanian lahan kering & 6599,43 & 4426,62 & 6599,43 & 6599,43 & 2500,42 \\
\hline Pertanian lahan kering campur semak & & & & &
\end{tabular}

Keterangan :

Modeling I : : Area tanah terbuka dialihfungsikan menjadi hutan

Modeling II : Area pertanian dialihfungsikan menjadi sistem agroforestri

Modeling III : : Area hutan $30 \%$ dari wilayah DAS

Modeling IV : : Area tanah terbuka, pertanian lahan kering dan 4.099 ha pertanian lahan kering campur semak belukar dialihfungsikan menjadi sistem agroforestri 


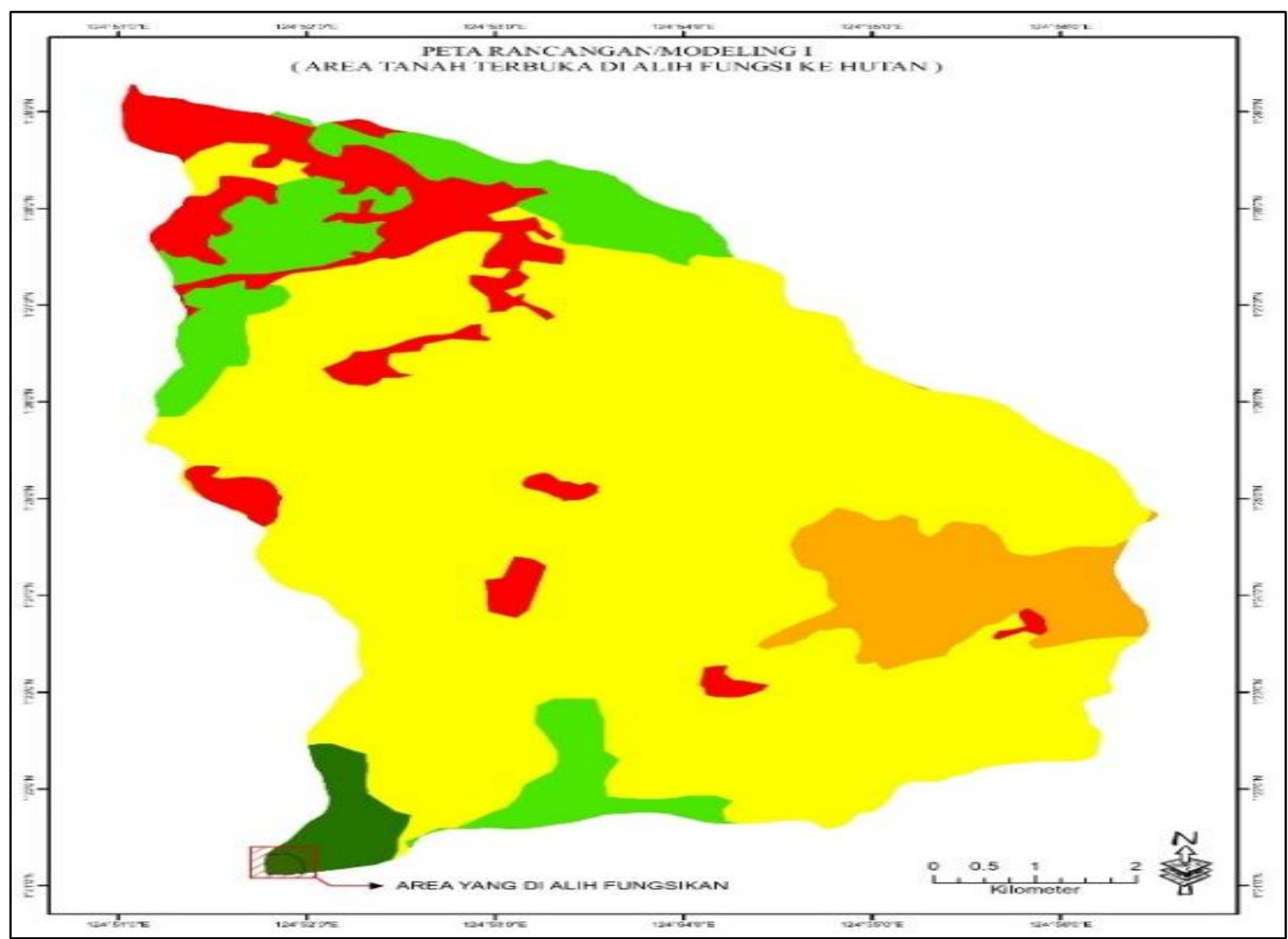

Gambar 5. Modeling I

(Figure 5. Modeling I)

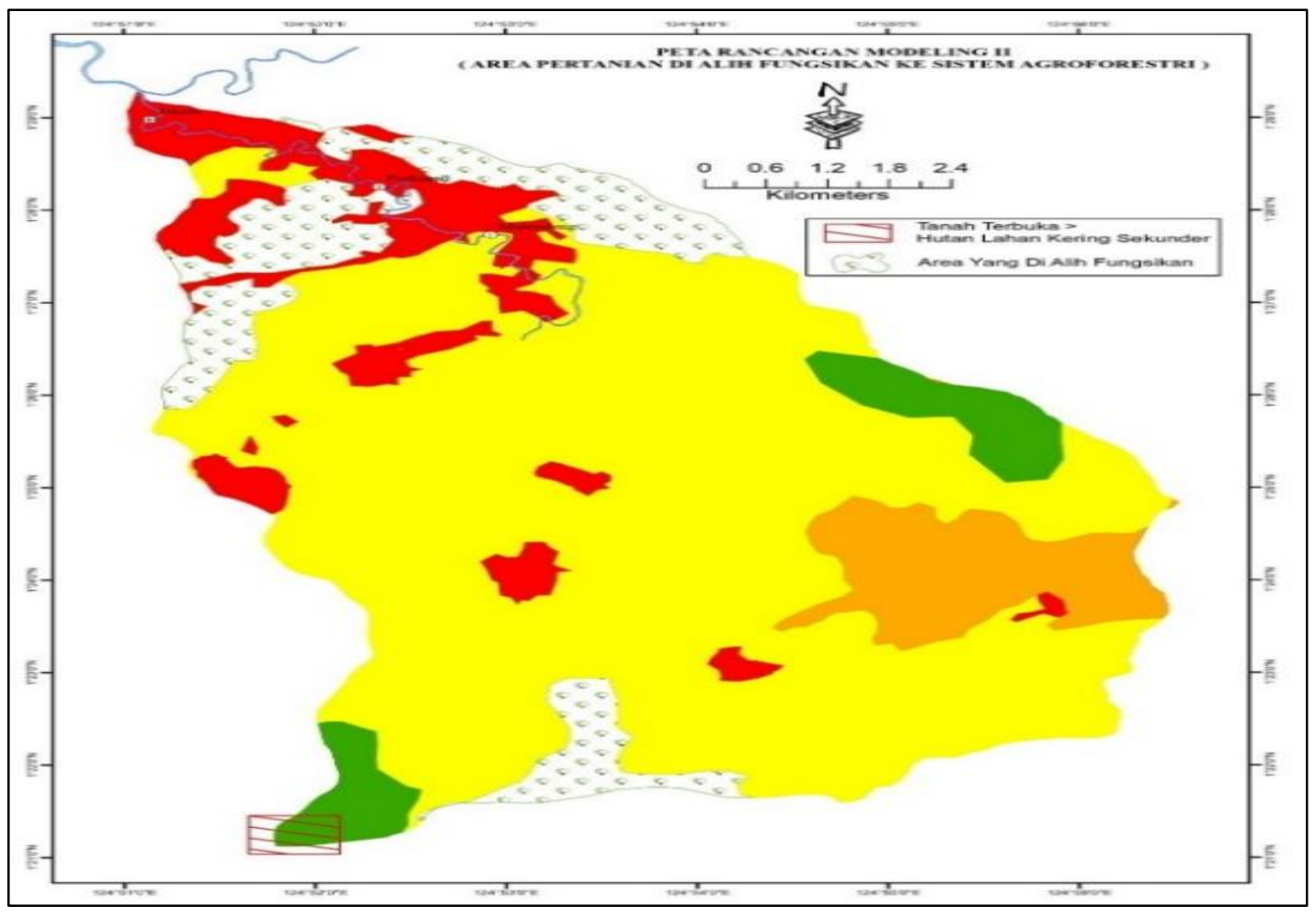

Gambar 6. Modeling II

(Figure 6. Modeling II) 


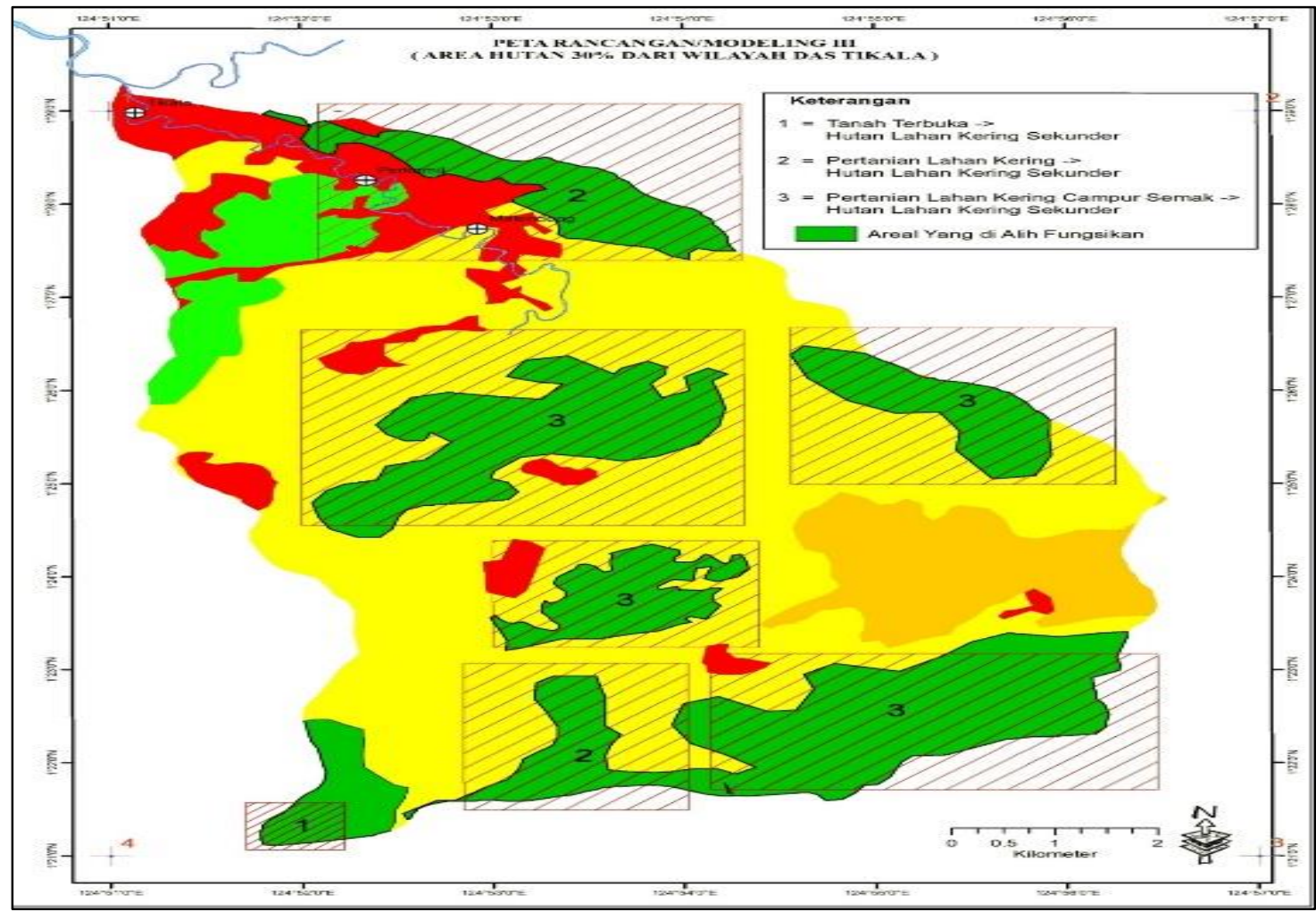

Gambar 7. Modeling III

(Figure 7. Modeling III)

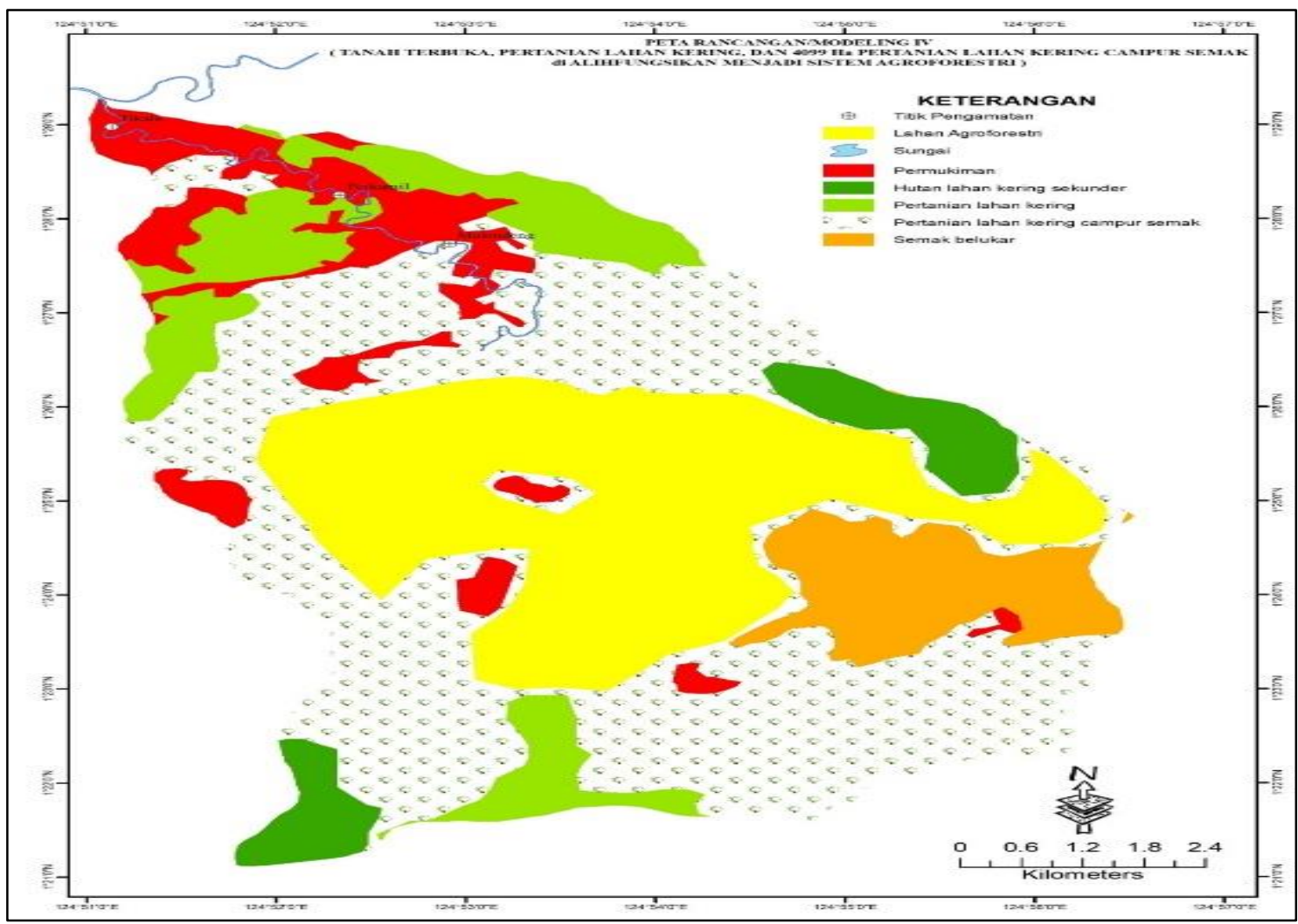

Gambar 8. Modeling IV

(Figure 8. Modeling IV) 


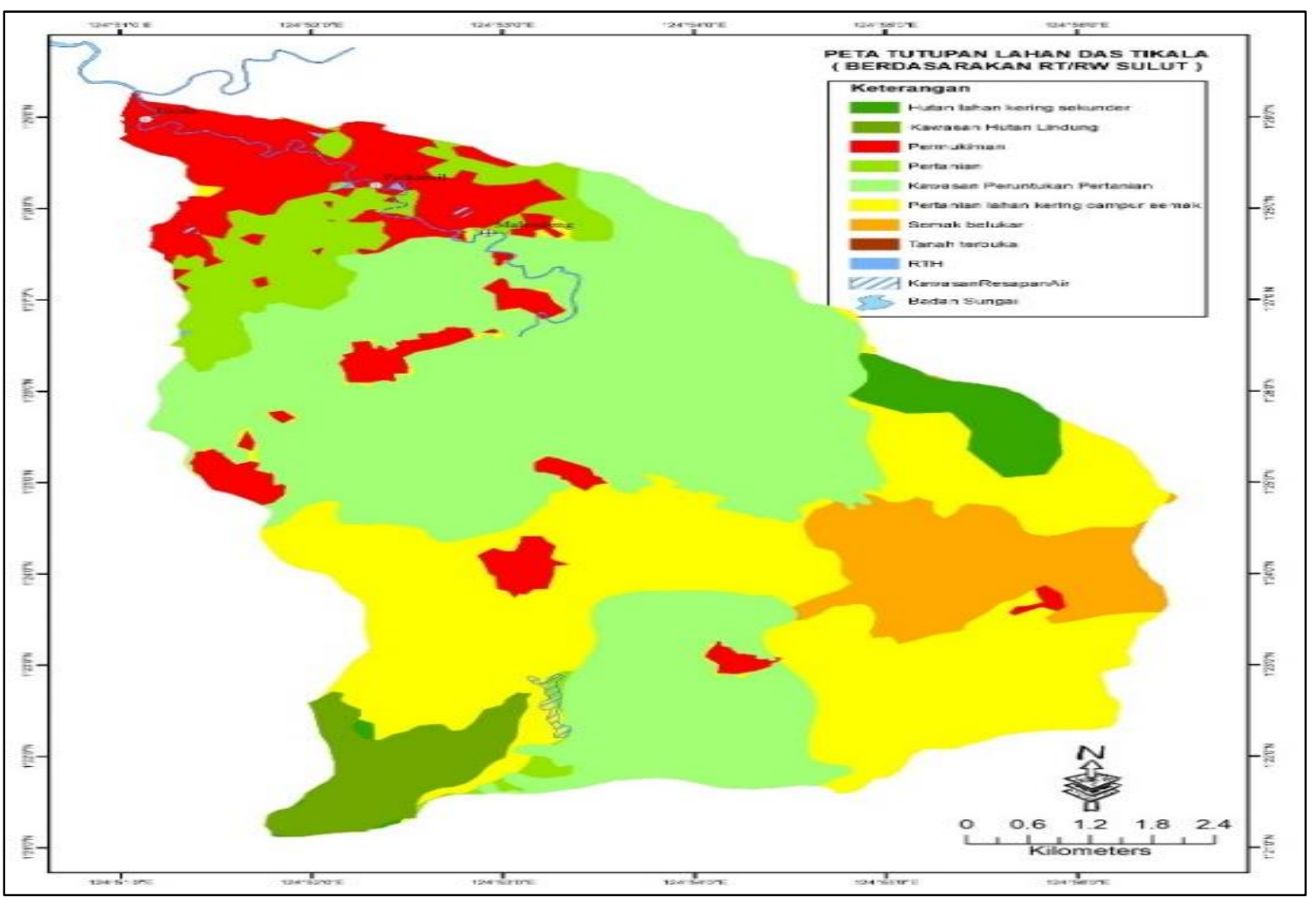

Gambar 9. Modeling V

(Figure 9. Modeling V)

Tabel 9. Batas Kritis Curah Hujan

(Table 9. Critical Rainfall Limit)

\begin{tabular}{cccc}
\hline Modeling & $\begin{array}{c}\text { Tikala } \\
(\mathrm{mm} / \mathrm{jam})\end{array}$ & $\begin{array}{c}\text { Perkamil } \\
(\mathrm{mm} / \mathrm{jam})\end{array}$ & $\begin{array}{c}\text { Malendeng } \\
(\mathrm{mm} / \mathrm{jam})\end{array}$ \\
\hline I & 12,5 & 38,9 & 10,7 \\
II & 13,5 & 41,9 & 11,5 \\
III & 16 & 49,5 & 13,6 \\
IV & 43,9 & 136,1 & 37,4 \\
Kondisi saat ini & 12,5 & 13,4 & 12,1 \\
\hline
\end{tabular}

Modeling V (Tutupan Lahan berdasarkan Rencana Tata Ruang Wilayah Provinsi Sulawesi Utara Tahun 2014-2034)

Modeling yang terakhir adalah modeling berdasarkan rencana tata ruang wilayah Provinsi Sulawesi Utara tahun 2014-2034, dari hasil analisis yang telah dibuat diketahui bahwa nilai koefisien limpasan untuk model ini adalah 0,130 dapat dilihat dalam Tabel 7, sehingga dapat dilihat dalam Tabel 7 bahwa nilai kapasitas maksimum dalam model ini adalah $167,99 \mathrm{~mm}^{3} / \mathrm{jam}$ untuk curah hujan 50 $\mathrm{mm} / \mathrm{jam}$ dan 335,98 mm3/jam untuk curah hujan $100 \mathrm{~mm} / \mathrm{jam}$. Jika dibandingkan dengan kapasitas saluran sungai saat ini (Tabel 5) maka akan terjadi luapan air karena kapasitas sungai tidak mencukupi menampung debit maksimum.

\section{Batas Kritis Curah Hujan DAS Tikala}

Batas kritis curah hujan atau bisa juga disebut ambang batas curah hujan merupakan curah hujan harian yang menghasilkan aliran permukaan sama dengan kapasitas saluran sungai dan berlangsung minimal sama dengan waktu konsentrasi. Tabel 9 menunjukkan batas kritis curah hujan berdasarkan modeling tutupan lahan di 3 lokasi penelitian. 
Berdasarkan Tabel 9 batas kritis curah hujan yang paling rendah untuk seluruh modeling yaitu $10,7 \mathrm{~mm} / \mathrm{jam}$ pada modellig I lokasi pengamatan Malendeng. Sedangkan batas kritis curah hujan yang tertinggi yaitu $136,1 \mathrm{~mm} / \mathrm{jam}$ pada modeling IV lokasi pengamatan Perkamil. Hal ini berarti bahwa pada modeling IV lokasi pengamatan Perkamil adalah lokasi yang mampu menampung curah hujan yang besar.

\section{Perbandingan antara Modeling Tutupan Lahan I, II, III, IV, Tutupan Lahan saat ini dan Tutupan Lahan sesuai RTRW}

Perbandingan antara keempat modeling tutupan lahan, tutupan lahan saat ini dan tutupan lahan sesuai RTRW bahwa model I, II, dan III tidak sesuai untuk tutupan lahan saat ini meskipun nilai koefisien limpasan lebih kecil dibandingkan dengan nilai koefisien limpasan saat ini akan tetapi nilai kapasitas sungai saat ini belum mampu menampung debit maksimum untuk ke 3 model (Tabel 5 dan Tabel 6) dan untuk model yang ke IV jika dibandingkan dengan tutupan lahan saat ini bahwa model yang ke IV ini mampu menampung debit maksimum dengan curah hujan $50 \mathrm{~mm} / \mathrm{jam}$ di lokasi Perkamil walaupun untuk curah hujan 100 mm/jam masih melampaui kapasitas sungai yang ada (Tabel 5). Tutupan lahan DAS Tikala sesuai rencana tata ruang wilayah (RTRW) Provinsi SULUT jika dibandingkan dengan model I tutupan lahan sesuai RTRW ini memiliki nilai debit maksimum yang lebih kecil dari model I ini, tetapi jika dibandingkan dengan model II, III dan IV nilai debit maksimum tutupan lahan berdasarkan RTRW ini masih melebihi ke 3 model ini. Dan untuk tutupan lahan saat ini jika dibandingkan dengan tutupan lahan berdasarkan RTRW nilai debit maksimum tutupan lahan berdasarkan RTRW lebih kecil dibandingkan nilai debit maksimum tutupan lahan saat ini, akan tetapi nilai debit maksimum tutupan lahan berdasarkan RTRW ini masih melampaui nilai kapasitas sungai di DAS Tikala (Tabel 5).

\section{KESIMPULAN DAN SARAN}

\section{Kesimpulan}

Nilai kapasitas saluran sungai DAS Tikala adalah $36,39 \mathrm{~m}^{3} / \mathrm{s}, 131,58 \mathrm{~m}^{3} / \mathrm{s}$ dan $45,29 \mathrm{~m}^{3} / \mathrm{s}$.
Serta debit limpasan maksimum dengan tutupan lahan saat ini sebesar $181,25 \mathrm{~m}^{3} / \mathrm{s}$ dengan intensitas curah hujan $50 \mathrm{~mm} / \mathrm{jam}$ dan $362,51 \mathrm{~m}^{3} / \mathrm{s}$, selanjutnya intensitas dengan curah hujan melebihi 100 $\mathrm{mm} / \mathrm{jam}$ maka kapasitas saluran akan ter-lampaui dan modeling tutupan lahan yang tidak melampaui kapasitas saluran sungai Tikala adalah Modeling IV area tanah terbuka, pertanian lahan kering dan 4.099 ha pertanian lahan kering campur semak belukar dialihfungsikan menjadi sistem agro-forestri dengan intensitas curah hujan $50 \mathrm{~mm} / \mathrm{jam}$.

\section{Saran}

Perlu dilakukan penelitian penentuan koefisien limpasan aliran permukaan sistem agroforestri kemudian perlu diadakan rehabilitasi DAS untuk mengurangi dampak banjir ketika terjadi banjir dan perlu diadakan pelebaran sungai, pengerukan dasar sungai di daerah hilir atau dibuat talud agar dapat menampung aliran air akibat curah hujan dengan intensitas tinggi.

\section{DAFTAR PUSTAKA}

Asdak. 2014. Hidrologi dan Pengelolaan Daerah Aliran Sungai. Gadjah Mada University Press. Yogyakarta.

BPDAS. 2014. Laporan Kejadian Banjir dan Tanah Longsor DAS Tondano, DAS Paniki, dan DAS Sario. Balai Pengelolaan DAS Tondano. Manado.

BPDAS. 2016. Peta Tutupan Lahan Sulawesi Utara. Balai Pengelolaan DAS Tondano. Manado.

Indarto. 2010. Hidrologi: Dasar Teori dan Contoh Aplikasi Model Hidrologi. Bumi Aksara. Jakarta.

Rinaldi, A., D. Pohan, dan I. R. Moe. 2018. Evaluasi Permasalahan Banjir Kota Manado Dengan Pemodelan Dua Dimensi. Karya Tulis IImiah Kementrian Pekerjaan Umum dan Perumahan Rakyat. 15 Oktober 2018. Manado. 
